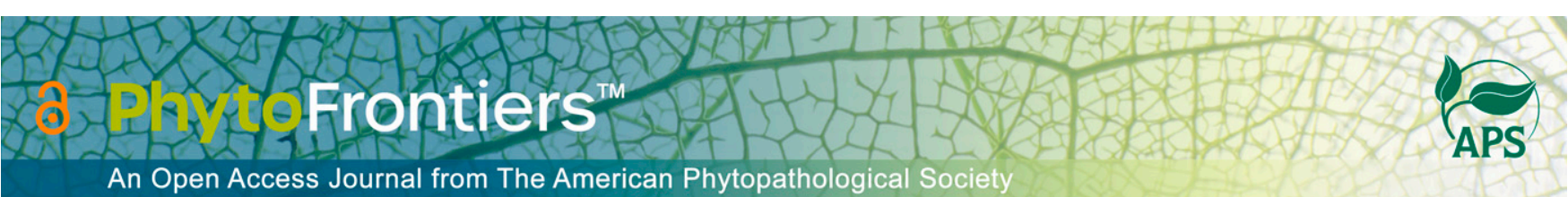

\title{
Research
}

\section{Effect of Ozone on Inactivation of Purified Pepper Mild Mottle Virus and Contaminated Pepper Seed}

\author{
John R. Stommel ${ }^{1,+}$ (D) | Judith M. Dumm ${ }^{1}$ John Hammond ${ }^{2}$ |
}

\begin{abstract}
${ }^{1}$ Genetic Improvement of Fruits and Vegetables Laboratory, U.S. Department of Agriculture, Agricultural Research Service, Beltsville Agricultural Research Center, Beltsville, MD 20705-2325

2 Floral and Nursery Plant Research Unit, U.S. Department of Agriculture, Agricultural Research Service, U.S. National Arboretum, Beltsville, MD 20705-2325
\end{abstract}

† Corresponding author: J. R. Stommel;
john.stommel@usda.gov

Accepted for publication 16 December 2020.
Mention of trade names or commercial products is solely for the purpose of providing specific

information and does not imply recommendation or endorsement by the United States Department of Agriculture.

The author(s) declare no conflict of interest.

\begin{abstract}
Pepper mild mottle virus (PMMoV) is a major viral pathogen of pepper (Capsicum spp.). $\mathrm{PMMoV}$ is readily mechanically transmitted and is seed transmissible. Trisodium phosphate (TSP) treatment is commonly used to reduce the level of viable PMMoV in contaminated seed. Ozone is efficacious in disinfecting fungal-contaminated seed and disrupting bacterial and viral pathogens on various substrates. The purpose of this study was to evaluate efficacy of ozone and chemical treatment on PMMoV viability. Treated pepper seed infectivity was evaluated via bioassay with Nicotiana benthamiana. Symptoms of PMMoV infection were not observed in bioassays of TSP-treated seed. Sufficient viable PMMoV remained on ozone-treated seed to cause infection, which was confirmed by ELISA. Neither treatment affected seed germination. Ozone treatment of purified PMMoV was assessed to determine the extent, if any, of PMMoV inactivation by ozone. At the low PMMoV concentration ( $0.01 \mathrm{mg} / \mathrm{ml})$, 14-h ozone exposure eliminated infectivity as determined by $N$. benthamiana bioassays with ELISA confirmations. At the higher PMMoV concentration $(0.1 \mathrm{mg} / \mathrm{ml})$, ozone treatment was insufficient to prevent infection. Ozone inactivation of purified PMMoV was quantified via bioassay using the local lesion host $N$. glutinosa and quantitative real-time PCR. Ozone exposure reduced lesion counts and PMMoV concentration, and PMMoV degradation increased with exposure time. Although PMMoV infection was eliminated at the low PMMoV concentration, bioassays using naturally infected seed and purified PMMoV preparations at relatively higher concentrations demonstrated that ozone is not efficacious as a standard treatment to sufficiently reduce levels of infective PMMoV in contaminated pepper seed.
\end{abstract}

Keywords: Capsicum, ozone, pepper mild mottle virus, seed transmission

Pepper mild mottle virus (PMMoV) is a serious viral pathogen of Capsicum spp. and occurs worldwide (Genda et al. 2005; Nagai 1981). PMMoV is one of at least four species of Tobamovirus that may cause significant losses in field and greenhouse pepper production. Infected plants are characteristically stunted with mild leaf mottling and puckering (Alonso et al. 1989; Nagai 1981). Fruit size is similarly reduced, and fruit may 
exhibit distorted shape and necrotic lesions. PMMoV is classified as a tobamovirus. It is a nonenveloped, protein encapsidated, rod-shaped particle containing a positive-sense $6.3-\mathrm{kb}$ singlestranded RNA (Wetter et al. 1984). Similar to other tobamoviruses such as tobacco mosaic virus, PMMoV may be mechanically transmitted by workers and is transmitted by contaminated seed, infecting the germinating seedling as it breaks through the seed coat (Lamb et al. 2001; Lewandowski 1999), or later transmitted to roots damaged by handling during transplanting (Broadbent 1965). PMMoV is persistent on seed and contaminated surfaces (Jarret et al. 2008; Lewandowski 1999). In seed, PMMoV and other tobamoviruses are localized on and in the seed coat but usually not the developing embryo tissue (Demski 1981; Genda et al. 2005), although cucumber green mottle mosaic virus has been detected in the perisperm-endosperm envelope, which surrounds the embryo within the seed coat (Shargil et al. 2019).

Chemical and heat treatments have been utilized to reduce the incidence of PMMoV and other tobamoviruses in contaminated pepper seed. Soaking seed in solutions of $10 \%$ trisodium phosphate (TSP), 9\% hydrochloric acid solution, calcium hypochlorite solution, and $4.2 \%$ sodium hypochlorite reduce but do not eliminate tobamovirus in contaminated seed (Crowley 1957; Lamb et al. 2001; Nagai 1981). Similarly, dry heat at $70^{\circ} \mathrm{C}$ for 1 to 3 days reduces but does not entirely eliminate tobamovirus in contaminated seed lots. In treatment combining TSP followed by dry heat for $3 \mathrm{~h}$, PMMoV was reportedly not detectable by bioassay using Nicotiana glutinosa (Toyoda et al. 2004).

Incomplete efficiency of chemical solutions and dry heat for inactivation of seed-transmitted pathogens has generated new research to evaluate the efficacy of ozone to kill bacteria and viruses for sanitation in medical applications (Finch and Fairbairn 1991; Gupta and Brintnell 2014; Laroussi 2005), fresh and processed food (Restaino et al. 1995; Zhao and Cranston 1995), and, more recently, seed disinfestation (Kang et al. 2015). Through the oxidation of double bonds, ozone can inactivate biological contaminants. Under some conditions, ozone can work up to 3,000 times faster and is 150 times stronger than chlorine for killing bacteria, fungi, and other pathogens (Dyas et al. 1983). Only fluorine exceeds the oxidative strength of ozone. Ozone is a reactive oxygen species (ROS) that rapidly decays into additional short half-life ROS that cause oxidative damage to biological molecules. Ozone can degrade organic material and disrupt the integrity of cell walls. Unsaturated lipids, carbohydrates, and nucleic acids are damaged by ozone. Damage to lipids and nucleic acids is the major cause of viral inactivation (Roy et al. 1981; Shinriki et al. 1978).

The antimicrobial activity of ozone has been demonstrated to control Xanthomonas contamination of rice seed (Mohan et al. 2005), reduce Salmonella enterica and Escherichia coli contamination of tomato, lettuce, and cantaloupe seed (Trinetta et al. 2011), and reduce microbial contamination of alfalfa seed (Kwack et al. 2014; Rajkowski and Rice 2004). Three-minute ozone exposure in air had no significant effect on seed germination and was sufficient for disinfestation of pea, wheat, and barley seed contaminated with Alternaria spp., Penicillium spp., and Aspergillus spp. (Ciccarese et al. 2007). ROS generated in water by ozone were demonstrated to be fungicidal against spores of Fusarium causing rice bakanae disease (Kang et al. 2015).

Murray et al. (2008) utilized an ozone delivery system to inactivate a series of enveloped and nonenveloped mammalian and avian viruses. Lipid envelopes of enveloped viruses exhibited extreme sensitivity to ozone via lipid peroxidation and subsequent envelope damage. Nonenveloped viruses were more resistant to ozone, but with longer exposure time they exhibited protein shell damage, resulting in reduced infectivity. Our study evaluates the efficacy of ozone in reducing infectivity of the nonenveloped tobamovirus PMMoV. Ozonetreated purified PMMoV and naturally contaminated pepper seed were evaluated.

\section{MATERIALS AND METHODS}

\section{Pepper seed sources}

Seed of four $C$. annuum pepper cultivars was commercially purchased: Keystone Resistant Giant and California Wonder from Holmes Seed Company (Canton, $\mathrm{OH}$ ) and Purple Beauty and Sweet Banana from Horticultural Products and Services Seed Company (Randolph, WI). Seed contaminated with PMMoV was extracted from four PMMoV-infected $C$. baccatum accessions (08C244, 08C332, 08C350, and 08C361) grown at the U.S. Department of Agriculture, Beltsville Agricultural Research Center, Beltsville, Maryland. A high incidence of PMMoV contamination in the selected $C$. baccatum seed lots was previously verified via ImmunoStrip assays for PMMoV (Agdia, Elkhart, IN).

\section{Pepper seed treatment}

Untreated pepper seed. For each of the four pepper cultivars and four $C$. baccatum accessions, a minimum of 105 seeds were transferred to paper coin envelopes in triplicate and stored at $4{ }^{\circ} \mathrm{C}$, $25 \%$ humidity until use.

Ozone-exposed pepper seed. For seed of all cultivars and $C$. baccatum accessions, a minimum of 105 seeds were spread out in $100 \times 15$-mm open plastic Petri dishes, in triplicate, and exposed to ozone (20 ppm) for $14 \mathrm{~h}$ in a Sani Sport/Sani DefenX Supreme (Sani Sport, St. Laurent, QC) continuously generating ozone chamber using a customized control board for extended exposure times. Manufacturer instructions were followed to program the 14-h ozone generation time. Ozone-exposed seed was transferred to paper coin envelopes and stored at $4^{\circ} \mathrm{C}, 25 \%$ humidity until use.

TSP chemical-treated pepper seed. For each of the eight cultivars and $C$. baccatum accessions, a minimum of 105 seeds were transferred to nylon mesh bags, in triplicate. Bundled seed was agitated in a solution of $10 \%$ TSP w/v and $0.0002 \%$ Triton $\mathrm{X}-100 \mathrm{v} / \mathrm{v}$ for $1 \mathrm{~h}$ using a magnetic stirrer, rinsed for $5 \mathrm{~min}$ in flowing tap water, agitated a second time in a fresh solution of $10 \% \mathrm{TSP} \mathrm{w} / \mathrm{v}$ and $0.0002 \%$ Triton X-100 v/v for $1 \mathrm{~h}$, rinsed for $5 \mathrm{~min}$ with tap water, agitated in a $0.5 \%$ sodium hypochlorite $\mathrm{w} / \mathrm{v}$ solution for $10 \mathrm{~min}$, and rinsed for $20 \mathrm{~min}$ with tap water. Treated seed was dried overnight on clean paper towels, transferred to paper coin envelopes, and stored at $4{ }^{\circ} \mathrm{C}, 25 \%$ humidity until use.

\section{Purification of PMMoV, and ozone treatment}

An isolate of PMMoV originally from a sweet pepper plant grown from contaminated seed was transferred to Nicotiana benthamiana by grinding symptomatic pepper leaves in an estimated 10 volumes of $1 \% \mathrm{~K}_{2} \mathrm{HPO}_{4}$ to which a small amount of Celite was added as an abrasive, and gentle inoculation of three to five leaves of plants with six to eight expanded leaves. Presence of PMMoV was verified using (i) PMMoV-specific ImmunoStrips, following the manufacturer's protocol (Agdia); (ii) reverse transcription PCR using PMMoV-specific primers TobF/TobR or TobF/PMMoV-R2 (TobF, CGTTGGGCAATCAGTTTCAAAC; TobR, CCCTTCGATTTAAGTGGAGGGA; PMMoV-R2, ACTCG CGCTCTCGAACAGAGCTTG), designed from alignments of the sequences of multiple PMMoV isolates and other tobamovirus species; 
and (iii) transmission electron microscopy of leaf extracts negatively stained with sodium phosphotungstic acid (PTA). Purified virus was prepared from systemically infected leaves of $N$. benthamiana harvested 2 to 3 weeks postinoculation and stored frozen at $-20^{\circ} \mathrm{C}$ until extraction; the purification protocol of Gooding and Hiebert (1967) modified by addition of a high-speed centrifugation step (27,000 rpm, $2.5 \mathrm{~h}$, Beckman Type 50.2 rotor at $4^{\circ} \mathrm{C}$ ) over a $5-\mathrm{ml}$ pad of $30 \%$ sucrose in $10 \mathrm{mM}\left(\mathrm{K}_{2} \mathrm{H} / \mathrm{KH}_{2}\right) \mathrm{PO}_{4}, \mathrm{pH} 7.2$, following two rounds of polyethylene glycol precipitation and resuspension in $10 \mathrm{mM}\left(\mathrm{K}_{2} \mathrm{H} /\right.$ $\left.\mathrm{KH}_{2}\right) \mathrm{PO}_{4}, \mathrm{pH}$ 7.2. The final pellet was carefully drained and was resuspended in approximately $3 \mathrm{ml}$ of $10 \mathrm{mM}\left(\mathrm{K}_{2} \mathrm{H} / \mathrm{KH}_{2}\right) \mathrm{PO}_{4}, \mathrm{pH} 7.2$, per $100 \mathrm{ml}$ of the initial extraction volume. Concentration was determined spectrophotometrically, assuming that a $1 \mathrm{mg} / \mathrm{ml}$ solution has an $\mathrm{A}_{260 \mathrm{~nm}}$ of 3.0 OD. The purified preparation was stored at 4 to $5^{\circ} \mathrm{C}$ and was diluted as required in $10 \mathrm{mM}\left(\mathrm{K}_{2} \mathrm{H} / \mathrm{KH}_{2}\right) \mathrm{PO}_{4}, \mathrm{pH} 7.2$, for inoculations of test plants or for drying down for ozone exposure. Six $50-\mu l$ aliquots of 0.01 and $0.1 \mathrm{mg} / \mathrm{ml}$ purified $\mathrm{PMMoV}$ were vacuum dried in sterile polypropylene microfuge tubes. Dried preparations were exposed to ozone for 1 and $14 \mathrm{~h}$ in the Sani Sport ozone chamber as described above.

\section{Seed germination assay}

For each pepper cultivar or $C$. baccatum accession $\times$ treatment $\times$ replicate, 50 seeds were spread over two $100 \times 15$ $\mathrm{mm}$ Petri dishes lined with Whatman number 2 filter paper. The filter paper was moistened with distilled water to keep the seed moist. Petri dishes with covers were placed in a plastic container with a loose-fitting lid that allowed for air flow and incubated at $25^{\circ} \mathrm{C}$ for 14 days. The plates were checked daily, and distilled water was added as needed to keep seed moist. Germination was scored as percent sprouted seed over 14 days of incubation.

\section{Bioassays}

Seed inoculum. Ten dry seeds of each cultivar or C. baccatum accession $\times$ treatment $\times$ replicate were coarsely ground using a mortar and pestle for inoculation of each of three bioassay plant replicates. Two milliliters of $0.1 \mathrm{M}$ sodium phosphate $\left(\mathrm{Na}_{2} \mathrm{HPO}_{4} /\right.$ $\mathrm{NaH}_{2} \mathrm{PO}_{4}$ ) buffer, $\mathrm{pH} 7.0$, and approximately $2.5 \mathrm{~mm}^{3}$ of Celite were added to ground seed preparations, and the preparation was further ground to a fine slurry. Greenhouse-grown $N$. glutinosa and $N$. benthamiana with six to eight fully expanded true leaves were utilized for bioassays. Seedlings were raised in a propagation greenhouse free of virus-infected plants and were transferred to a separate greenhouse for bioassay tests; both greenhouses were maintained under nominal day/night conditions of approximately $24^{\circ} \mathrm{C} / 21^{\circ} \mathrm{C}$, under natural daylight with supplemental light as necessary under cloudy conditions and to extend day length to $14 \mathrm{~h}$ as required. Five leaves of each $N$. benthamiana plant were mechanically inoculated with gentle rubbing of ground seed preparations over the entire upper leaf surface. At 7 and 15 days postinoculation, N. benthamiana was scored visually as positive or negative for symptoms of systemic PMMoV infection including stunting, leaf mottling, and leaf curl. Additionally, $N$. benthamiana leaf tissue was collected 15 days postinoculation and stored at $-20^{\circ} \mathrm{C}$. The frozen leaf tissue was ground either in mesh sample bags (Agdia) or using a FastPrep24 bead beater homogenizer with lysing matrix A (MP Biomedicals, Irvine, CA). Extraction efficiency was similar between methods. Double antibody sandwich ELISA with commercial antisera for PMMoV (Agdia) was performed using ground $N$. benthamiana leaf tissue to test for the presence of PMMoV antigens and absorbance measured on a plate reader (SpectraMaxPlus, Molecular Devices, San Jose, CA).

Purified PMMoV inoculum. Dried purified PMMoV ozonetreated samples were resuspended in $50 \mu \mathrm{l}$ of $50 \mathrm{mM}$ potassium phosphate $\left(\mathrm{K}_{2} \mathrm{HPO}_{4} / \mathrm{KH}_{2} \mathrm{PO}_{4}\right)$ buffer, $\mathrm{pH} 7.2$, returning samples to original volume prior to drying. For each concentration $\times$ treatment $\times$ replicate, $20 \mu \mathrm{l}$ of sample was pipetted onto a single leaf of each $N$. benthamiana and $N$. glutinosa plants using three bioassay plant replicates and mechanically inoculated with gentle rubbing as described for seed inoculum preparations. PMMoV infection of $N$. benthamiana was scored as described for plants

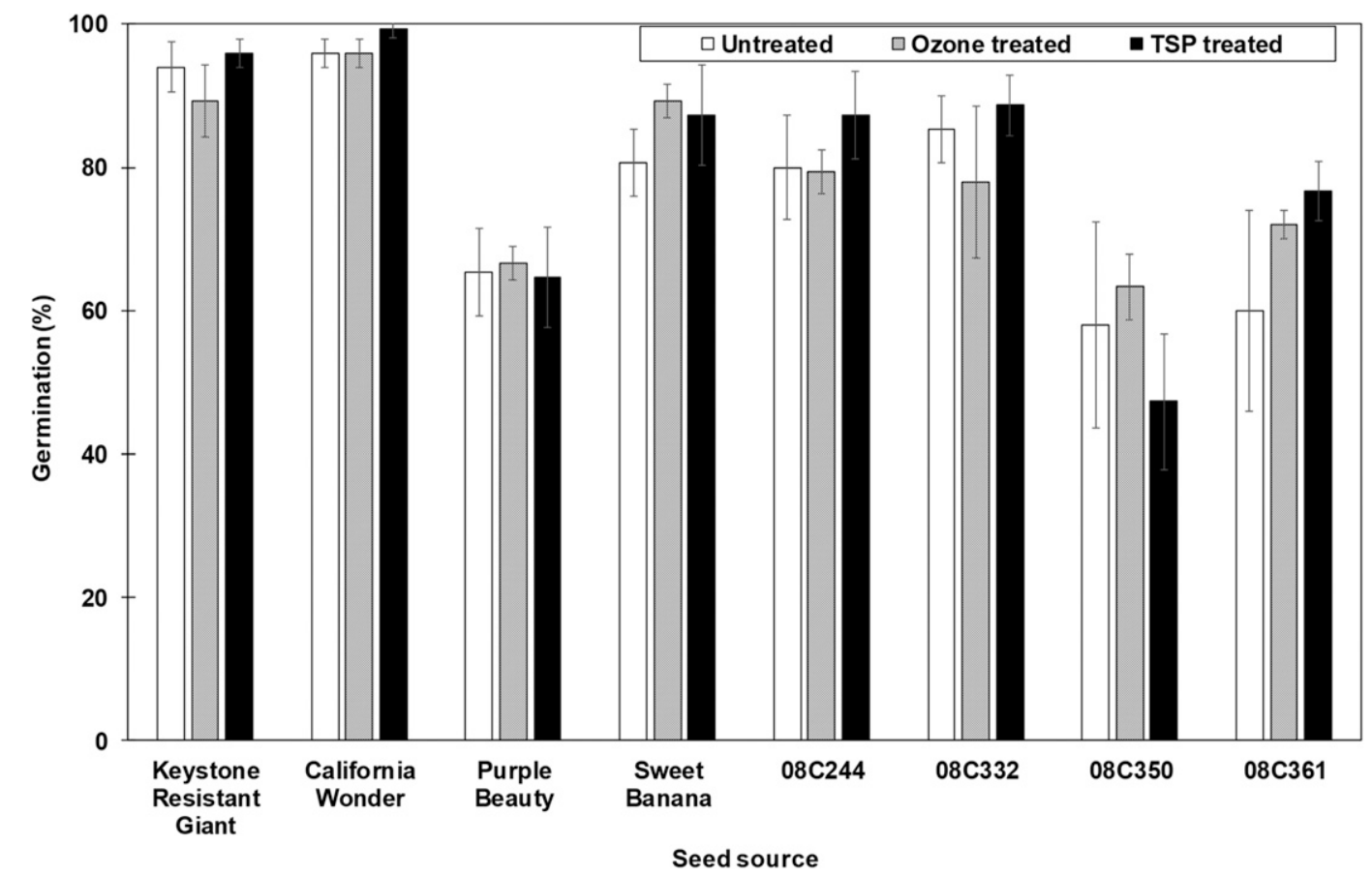

FIGURE 1

Effect of ozone exposure $(14 \mathrm{~h})$ and trisodium phosphate (TSP, 10\% w/v) wash treatments on pepper seed germination. 
inoculated with seed preparations. PMMoV infection of $N$. glutinosa was scored by counting the number of local lesions on inoculated leaves.

\section{PMMoV quantification}

RNA extraction. Purified PMMoV dried samples from respective ozone treatments were resuspended in $50 \mu \mathrm{l}$ of $50 \mathrm{mM}$ potassium phosphate $\left(\mathrm{K}_{2} \mathrm{HPO}_{4} / \mathrm{KH}_{2} \mathrm{PO}_{4}\right)$ buffer, $\mathrm{pH}$ 7.2, returning samples to original concentrations $(0.01$ and $0.1 \mathrm{mg} / \mathrm{ml}$ of PMMoV). Total RNA from original purified samples and resuspended dried samples was extracted using the RNeasy plant mini kit (Qiagen, Hilden, Germany). Each 50- $\mu 1$ PMMoV sample was disrupted by addition of $250 \mu$ l of kit Buffer RLT containing $\beta$-mercaptoethanol, mixing by inversion, and incubation at room temperature for $10 \mathrm{~min}$. Thereafter, the kit protocol was followed starting with the addition of 0.5 volume of ethanol to the disrupted sample. RNA was eluted in $2 \times 30-\mu$ l RNasefree water. Concentration and purity were measured using a NanoDrop-1000 spectrophotometer (NanoDrop Technologies, Wilmington, DE).

cDNA synthesis and quantitative real-time PCR (RT-qPCR). cDNA was synthesized from $6 \mu$ l of each extracted RNA using the ProtoScript first strand cDNA synthesis kit (New England Biolabs, Ipswich, MA) with random primer mix. RT-qPCR was performed using PMMoV primers described in the literature: PMMV-FP1-rev, 5'-GAGTGGTTTGACCTTAACGTTTGA-3' (forward primer, Haramoto et al. 2013) and PMMV-RP1, 5'TTGTCGGTTGCAATGCAAGT-3' (reverse primer, Zhang et al. 2006). Each 20- $\mu$ l reaction contained $2 \mu$ l of cDNA, 10 $\mu l$ of $2 \times$ iQ SYBR green supermix (Bio-Rad, Hercules, CA), and $0.2 \mu \mathrm{l}$ of each $10 \mu \mathrm{M}$ primer. Five threefold dilutions of known $\mathrm{PMMoV}$ concentration from purified PMMoV were assayed together with untreated and ozone-exposed samples for constructing a standard curve. All reactions were done in triplicate. RT-qPCR was performed on an iCycler iQ multicolor real-time detection system (Bio-Rad) using the cycling program described by Lightbourn et al. (2007). Where standard deviation between triplicates was $>0.5$, the outlier data point was discarded. Concentrations of untreated, dried, and ozone-exposed PMMoV samples were interpolated from the standard curve. The PCR product from $08 \mathrm{C} 332$ and $08 \mathrm{C} 361$ was purified using the DNA Clean \& Concentrator-5 kit (Zymo Research, Irvine, CA), cloned using the vector and cloning reaction from the TOPO-TA cloning kit (Invitrogen) with NEB stable competent E. coli (New England Biolabs), mini-prepped using the Zippy plasmid miniprep kit (Zymo Research), and sequenced commercially (Macrogen Corp., Rockville, MD). BLASTn of the 68-bp PCR product sequences against the GenBank nucleotide collection confirmed a $100 \%$ identity to PMMoV.

\section{Electron microscopy}

Negative staining of leaf extracts of $N$. benthamiana or $N$. glutinosa was performed by grinding leaf pieces with a small volume of PTA and transferring a drop of the liquid to a formvarcoated copper grid for examination in a JEOL 100CX II transmission electron microscope (JEOL USA, Peabody, MA). Preparations or dilutions of purified virus were mixed with an equal volume of PTA for application to a grid for examination. Grids were typically examined at microscope magnifications of $33,000,50,000$, and 66,000, and images were captured with an AMT HR digital camera system (Advanced Microscopy Techniques Corp., Woburn, MA).
RESULTS

\section{Seed treatment effect on germination}

Two seed treatment methods, immersion in TSP followed by sodium hypochlorite and exposure to ozone, were evaluated for their potential effect on germination of freshly treated seed. Seed of the four $C$. annuum cultivars and $C$. baccatum accessions treated with these chemical agents did not significantly affect percent germination relative to that observed for untreated seed (Fig. 1). Similarly, continuous exposure of seed to ozone for $14 \mathrm{~h}$ did not negatively affect percent seed germination.

\section{Efficacy of seed treatments}

Efficacy of TSP and sodium hypochlorite immersion versus extended ozone exposure was evaluated by bioassay using $N$. benthamiana. $N$. benthamiana plants inoculated with preparations of ground seed from presumed PMMoV-free commercial seed sources confirmed the absence of viable PMMoV on seed of Keystone Resistant Giant, California Wonder, Purple Beauty, and Sweet Banana (Table 1). The test also confirmed that PMMoV cross-contamination did not occur during treatment of seed in the laboratory. Bioassays using seed collected from PMMoV-infected plants of 08C244, 08C332, 08C350, and

\section{TABLE 1}

Visual assessment for pepper mild mottle virus (PMMoV) systemic infection in Nicotiana benthamiana plants 15 days after inoculation with ground extracts of untreated, ozone-treated, and trisodium phosphate

(TSP)-treated pepper seed of Capsicum аппиит cultivars and C. baccatum accessions

\begin{tabular}{|c|c|c|c|c|}
\hline \multirow[b]{2}{*}{ Seed source } & \multirow[b]{2}{*}{ Treatment $^{\mathrm{a}}$} & \multicolumn{3}{|c|}{ Response $^{\mathrm{b}}$} \\
\hline & & 1 & 2 (replicate) & 3 \\
\hline Not inoculated & Neg. ctrl. & - & - & - \\
\hline Buffer & Neg. ctrl. & - & - & - \\
\hline \multirow[t]{3}{*}{ Keystone Resistant Giant } & Untreated & - & - & - \\
\hline & Ozone & - & - & - \\
\hline & TSP & - & - & - \\
\hline \multirow[t]{3}{*}{ California Wonder } & Untreated & - & - & - \\
\hline & Ozone & - & - & - \\
\hline & TSP & - & - & - \\
\hline \multirow[t]{3}{*}{ Purple Beauty } & Untreated & - & - & - \\
\hline & Ozone & - & - & - \\
\hline & TSP & - & - & - \\
\hline \multirow[t]{3}{*}{ Sweet Banana } & Untreated & - & - & - \\
\hline & Ozone & - & - & - \\
\hline & TSP & - & - & - \\
\hline \multirow[t]{3}{*}{$08 \mathrm{C} 244$} & Untreated & + & + & + \\
\hline & Ozone & + & + & + \\
\hline & TSP & - & - & - \\
\hline \multirow[t]{3}{*}{ 08C332 } & Untreated & + & + & + \\
\hline & Ozone & + & + & + \\
\hline & TSP & - & - & - \\
\hline \multirow[t]{3}{*}{ 08C350 } & Untreated & + & + & + \\
\hline & Ozone & + & + & + \\
\hline & TSP & - & - & - \\
\hline \multirow[t]{3}{*}{ 08C361 } & Untreated & + & + & + \\
\hline & Ozone & + & + & + \\
\hline & TSP & - & - & - \\
\hline
\end{tabular}

${ }^{a}$ Neg. ctrl. $=$ negative control, and TSP $=10 \% \mathrm{w} / \mathrm{v}$ TSP

${ }^{\mathrm{b}}$ Bioassays were performed via inoculation of $N$. benthamiana with ground seed extracts prepared in phosphate buffer. Plants scored as positive (+) for infection exhibited stunting, leaf curl, and mottling characteristic of PMMoV systemic infection. Plants scored negative (-) for infection exhibited normal morphology. 
08C361 yielded characteristic systemic PMMoV symptoms including stunting and leaf curl in $N$. benthamiana plants inoculated with untreated ground seed preparations. Similar to bioassays of untreated PMMoV-contaminated seed, N. benthamiana plants inoculated with preparations from seed exposed to ozone for $14 \mathrm{~h}$ exhibited stunting and wilting, characteristic of systemic PMMoV infection. In contrast, bioassays using preparations from TSP and sodium hypochlorite-treated seed were negative for PMMoV symptoms.

Systemic infection of $N$. benthamiana with PMMoV was confirmed via ELISA. Consistent with PMMoV symptoms observed in $N$. benthamiana plants inoculated using preparations from untreated or 14-h ozone-treated seed from PMMoVcontaminated seed lots of 08C244, 08C 332, 08C 350 , and 08C361, ELISA tests were highly positive for those bioassays (Fig. 2). ELISA absorbance values for ozone-treated PMMoVcontaminated seed lots were not significantly different from untreated PMMoV-contaminated seed. Similar to the absence of PMMoV symptoms in $N$. benthamiana plants inoculated with preparations prepared from TSP and sodium hypochlorite-treated seed, ELISA was negative for PMMoV infection in those plants.

\section{Treatment effects on purified PMMoV}

Treatment of purified PMMoV was evaluated to directly assess the effects of sample drying and ozone exposure on PMMoV viability and degradation. For aqueous purified PMMoV at concentrations of 0.01 and $0.1 \mathrm{mg} / \mathrm{ml}$, symptoms typical of systemic PMMoV infection were observed in inoculated $N$. benthamiana plants (Table 2). Similarly, bioassay plants inoculated with dried purified PMMoV samples, as well as dried samples exposed to ozone for $1 \mathrm{~h}$, at both 0.01 and $0.1 \mathrm{mg} / \mathrm{ml}$ resulted in PMMoV-symptomatic plants. In contrast, $N$. benthamiana inoculated with dried preparations exposed to ozone for $14 \mathrm{~h}$ at the lower $0.01 \mathrm{mg} / \mathrm{ml}$ concentration but not the higher $0.1 \mathrm{mg} / \mathrm{ml}$ concentration produced asymptomatic plants. ELISA supported visual observations of symptomatic and asymptomatic bioassay plants. Positive ELISA readings were observed for $N$. benthamiana plants inoculated with untreated aqueous, dried, and dried purified PMMoV preparations exposed to ozone for $1 \mathrm{~h}$

\section{TABLE 2}

Visual assessment for pepper mild mottle virus (PMMoV) systemic infection in Nicotiana benthamiana plants 15 days after inoculation with untreated or treated purified PMMoV preparations

\begin{tabular}{lllll}
\hline & & \multicolumn{3}{c}{ Response $^{\mathrm{a}}$} \\
\cline { 3 - 6 } PMMoV concentration $(\mathrm{mg} / \mathrm{ml})$ & \multicolumn{1}{c}{ Treatment } & 1 & 2 (replicate) & 3 \\
\hline Not inoculated & Negative control & - & - & - \\
Buffer & Negative control & - & - & - \\
0.01 & Untreated $^{\mathrm{b}}$ & + & + & + \\
0.01 & Dried $^{\mathrm{c}}$ & + & + & - \\
0.01 & Dried, 1-h ozone & - & + & + \\
0.01 & Dried, 14-h ozone & - & - & - \\
0.1 & Untreated & + & + & + \\
0.1 & Dried & + & + & + \\
0.1 & Dried, 1-h ozone & - & + & + \\
0.1 & Dried, 14-h ozone & + & + & + \\
\hline
\end{tabular}

${ }^{a}$ Bioassays were performed via inoculation of $N$. benthamiana with purified PMMoV. Plants scored as positive (+) for infection exhibited stunting, leaf curl, and mottling characteristic of PMMoV systemic infection. Plants scored negative (-) for infection exhibited normal morphology.

b Aqueous purified PMMoV in $50 \mathrm{mM}$ potassium phosphate buffer.

${ }^{c}$ For treated purified PMMoV samples, aliquots of 0.01 and $0.1 \mathrm{mg} / \mathrm{ml}$ of purified PMMoV were vacuum dried, exposed to ozone for $1 \mathrm{~h}$ and $14 \mathrm{~h}$, and resuspended in $50 \mathrm{mM}$ potassium phosphate $\left(\mathrm{K}_{2} \mathrm{HPO}_{4} / \mathrm{KH}_{2} \mathrm{PO}_{4}\right)$ buffer, $\mathrm{pH}$ 7.2 , returning samples to original volume.

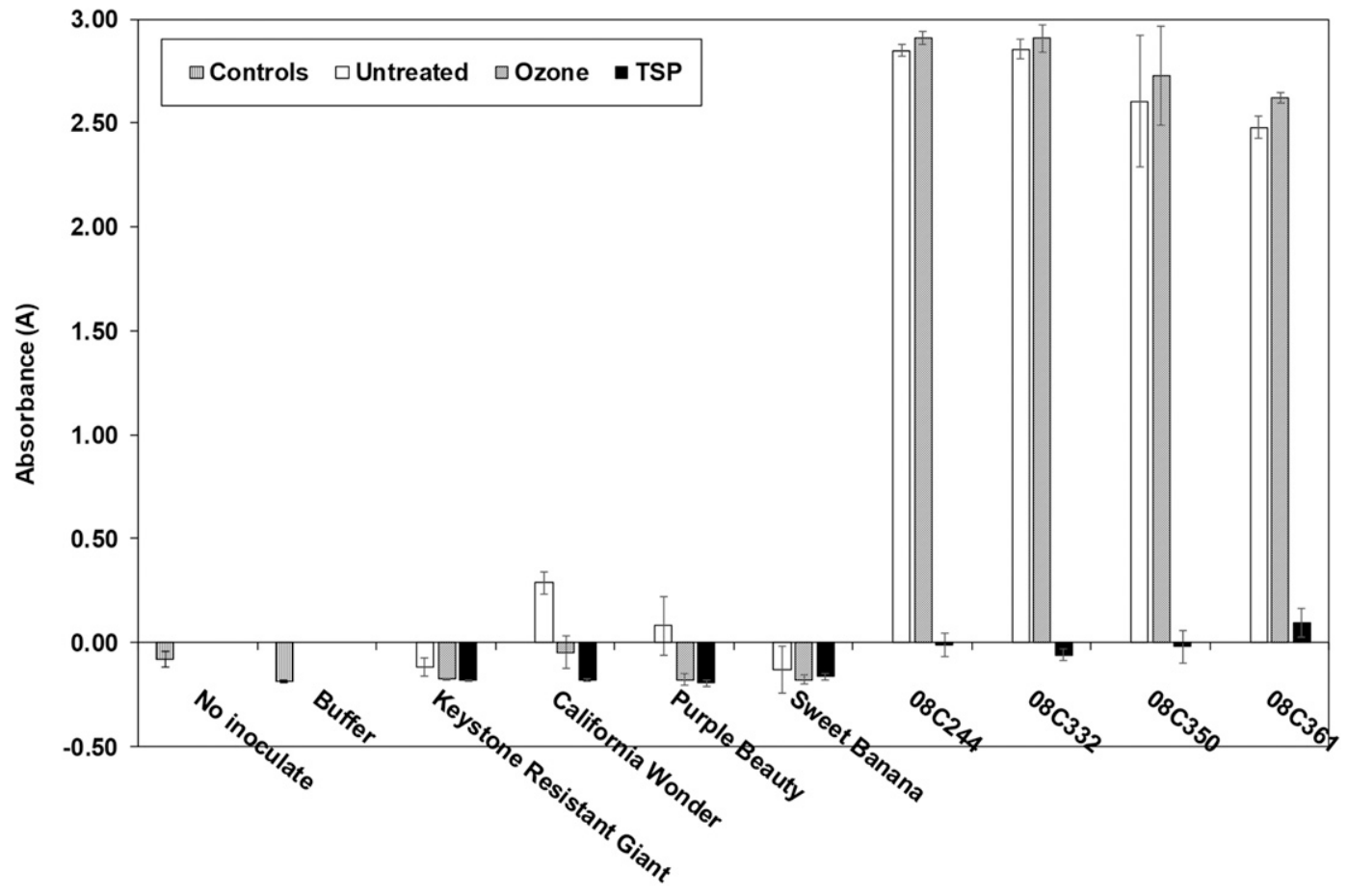

Inoculum seed source

FIGURE 2

Double antibody sandwich ELISA with commercial antisera for pepper mild mottle virus antigen detection in Nicotiana benthamiana plants 15 days after inoculation with ground pepper seed in phosphate buffer (TSP) prepared from untreated versus ozone-treated (14 h) seed of Capsicum annuum cultivars and C. baccatum accessions. 


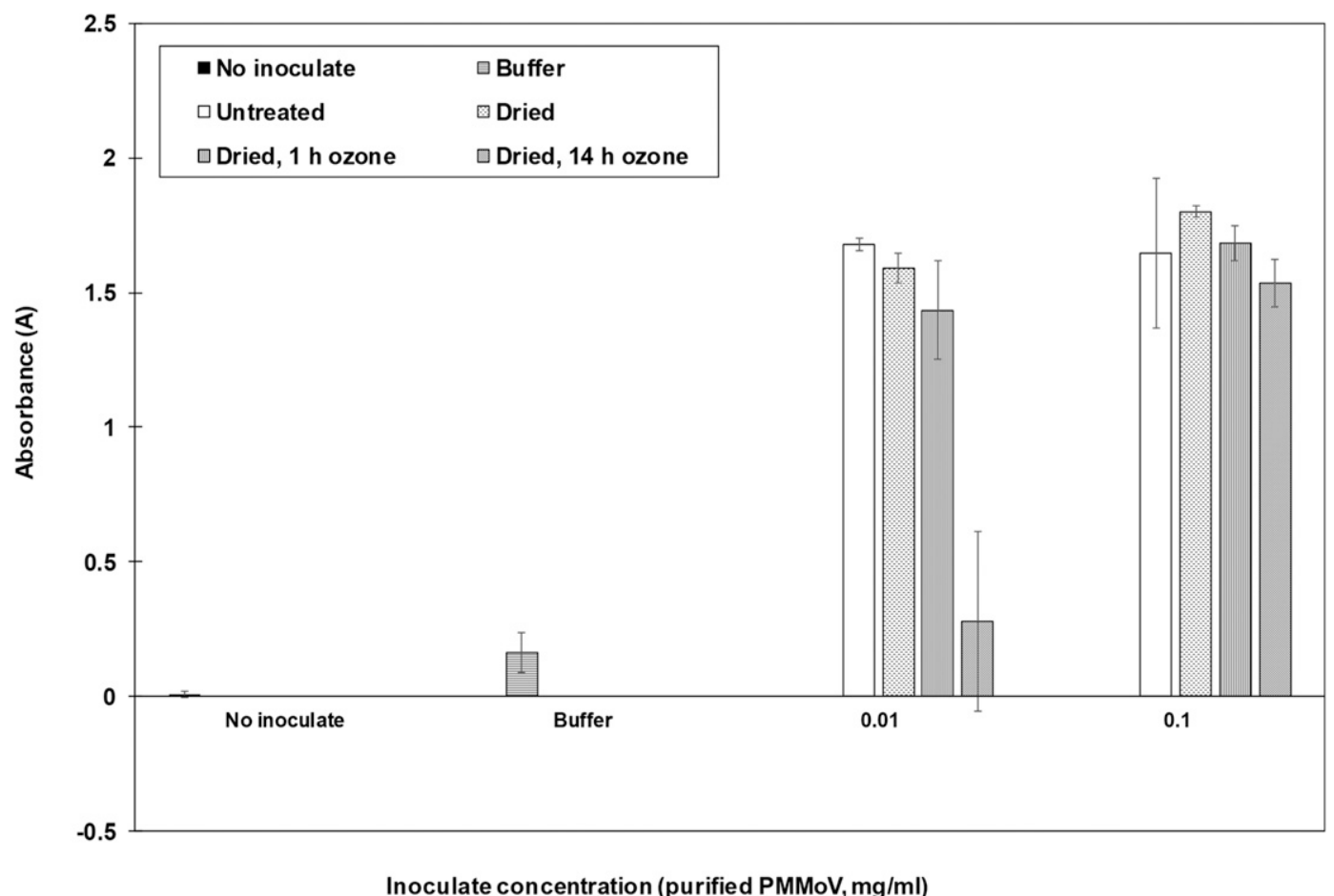

FIGURE 3

Double antibody sandwich ELISA with commercial antisera for pepper mild mottle virus (PMMoV) antigen detection in Nicotiana benthamiana plants 15 days after inoculation with untreated or ozone-treated purified PMMoV. For treated purified PMMoV samples, aliquots of 0.01 and $0.1 \mathrm{mg} / \mathrm{ml}$ of purified PMMoV were vacuum dried, exposed to ozone for $1 \mathrm{~h}$ and $14 \mathrm{~h}$, and resuspended in $50 \mathrm{mM}$ potassium phosphate $\left(\mathrm{K}_{2} \mathrm{HPO}_{4} / \mathrm{KH}_{2} \mathrm{PO}_{4}\right)$ buffer, $\mathrm{pH} 7.2$, returning samples to original volume.

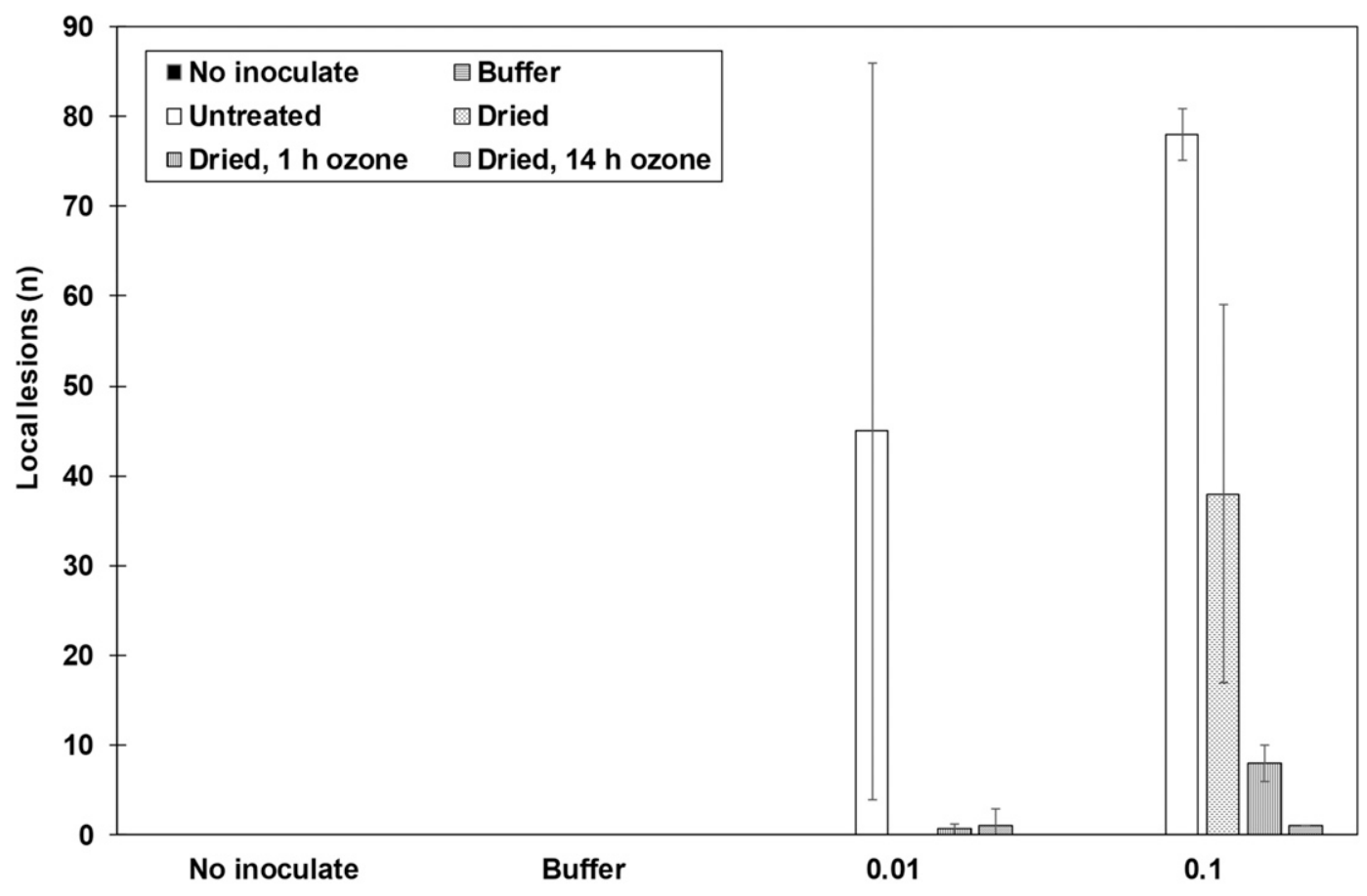

Inoculate concentration (purified PMMoV, $\mathrm{mg} / \mathrm{ml}$ )

FIGURE 4

Local lesion counts on Nicotiana glutinosa leaves in response to pepper mild mottle virus (PMMoV) infection 15 days after inoculation with untreated or ozone-treated purified PMMoV. For treated purified PMMoV samples, aliquots of 0.01 and $0.1 \mathrm{mg} / \mathrm{ml}$ of purified PMMoV were vacuum dried, exposed to ozone for $1 \mathrm{~h}$ and $14 \mathrm{~h}$, and resuspended in $50 \mathrm{mM}$ potassium phosphate $\left(\mathrm{K}_{2} \mathrm{HPO}_{4} / \mathrm{KH}_{2} \mathrm{PO}_{4}\right)$ buffer, $\mathrm{pH} 7.2$, returning samples to original volume. 
(Fig. 3). Consistent with observations of systemic infection, ELISA was highly positive for PMMoV infection in bioassay plants inoculated with dried purified PMMoV at $0.1 \mathrm{mg} / \mathrm{ml}$ preparations exposed to ozone for $14 \mathrm{~h}$, but not for plants inoculated with $0.01 \mathrm{mg} / \mathrm{ml}$ preparations exposed to ozone for $14 \mathrm{~h}$.

The local lesion host, $N$. glutinosa, was also inoculated with purified PMMoV at 0.01 and $0.1 \mathrm{mg} / \mathrm{ml}$ concentrations. Relative to bioassay plants inoculated with untreated purified aqueous PMMoV preparations, local lesion counts were significantly reduced in $N$. glutinosa plants inoculated with dried, dried and exposed to ozone for $1 \mathrm{~h}$, and dried and exposed to ozone for $14 \mathrm{~h}$ treatment preparations (Fig. 4). For the untreated aqueous treatment preparation, lesion count was not significantly different at the two PMMoV concentrations. At $0.1 \mathrm{mg} / \mathrm{ml}$ purified PMMoV, lesion count declined as a function of drying and duration of ozone exposure.

Concentrations of PMMoV in purified PMMoV preparations subjected to drying and ozone exposure were quantified using RT-qPCR. Relative to untreated aqueous preparations, PMMoV concentrations were reduced in dried preparations and dried preparations exposed to ozone (Fig. 5). At the higher $0.1 \mathrm{mg} / \mathrm{ml}$ PMMoV concentration, we were able to measure a decline in PMMoV concentration that was commensurate with the severity of the treatment. At the $0.1 \mathrm{mg} / \mathrm{ml}$ concentration, PCR-amplifiable $\mathrm{PMMoV}$ concentration in dried preparations exposed to ozone for $1 \mathrm{~h}$ was significantly less than the concentration in dried preparations. Similarly, PMMoV concentration in preparations exposed to ozone for $14 \mathrm{~h}$ was significantly less than those subjected to only 1-h ozone exposure.

\section{DISCUSSION}

Ozone is well documented as a disinfectant in medical and fresh and processed food applications to inactivate microorganisms including bacteria, fungi, and viruses (Hoff 1986; Khadre et al. 2001). Enveloped viruses exhibit high sensitivity to ozone exposure primarily as a result of initial ROS-mediated peroxidation of the lipid envelope. Enveloped viruses including human immunodeficiency virus type 1 (Carpendale and Freeberg 1991), vesicular stomatitis Indiana virus, herpes simplex virus type 1, vaccinia virus, and influenza A (Murray et al. 2008) are highly sensitive to inactivation by ozone. Nonenveloped viruses including adenovirus type 2 exhibited greater resistance to ozone and required nearly threefold longer exposure times for inactivation (Murray et al. 2008). Nonenveloped viruses consist of a protein-encapsidated single- or double-stranded nucleic acid core. Relative to the lipid envelope of enveloped viruses, the protein shells are more resistant to destruction by ozone. However, oxidation and peroxidation of proteins and resulting covalent modifications from ozone exposure that obstruct normal cellular functions also cause viral inactivation (Shacter 2000). Using transmission electron microscopy, Murray et al. (2008) documented lipid envelope and protein shell damage to ozonetreated enveloped and nonenveloped viruses, respectively. Roy et al. (1981) determined that ozone-mediated disruption of the protein coat did not prevent host cell adsorption of poliovirus-1, but rather extensive nucleic acid damage was the cause for viral inactivation.

Our results demonstrate that PMMoV exposure to ozone does result in viral inactivation; however, it is at levels insufficient to prevent viral transmission from contaminated seed. PMMoV particles are largely stabilized by protein-protein interactions, so oxidation/peroxidation changes that affect those interactions are the likely mechanism for viral RNA inactivation. Reduced RTqPCR values of ozone-treated virus, with greater effects at $14 \mathrm{~h}$ compared with $1 \mathrm{~h}$, support that likelihood. RT-qPCR is an effective measure of degradation because more intact gene transcripts in greater abundance become amplified sooner in

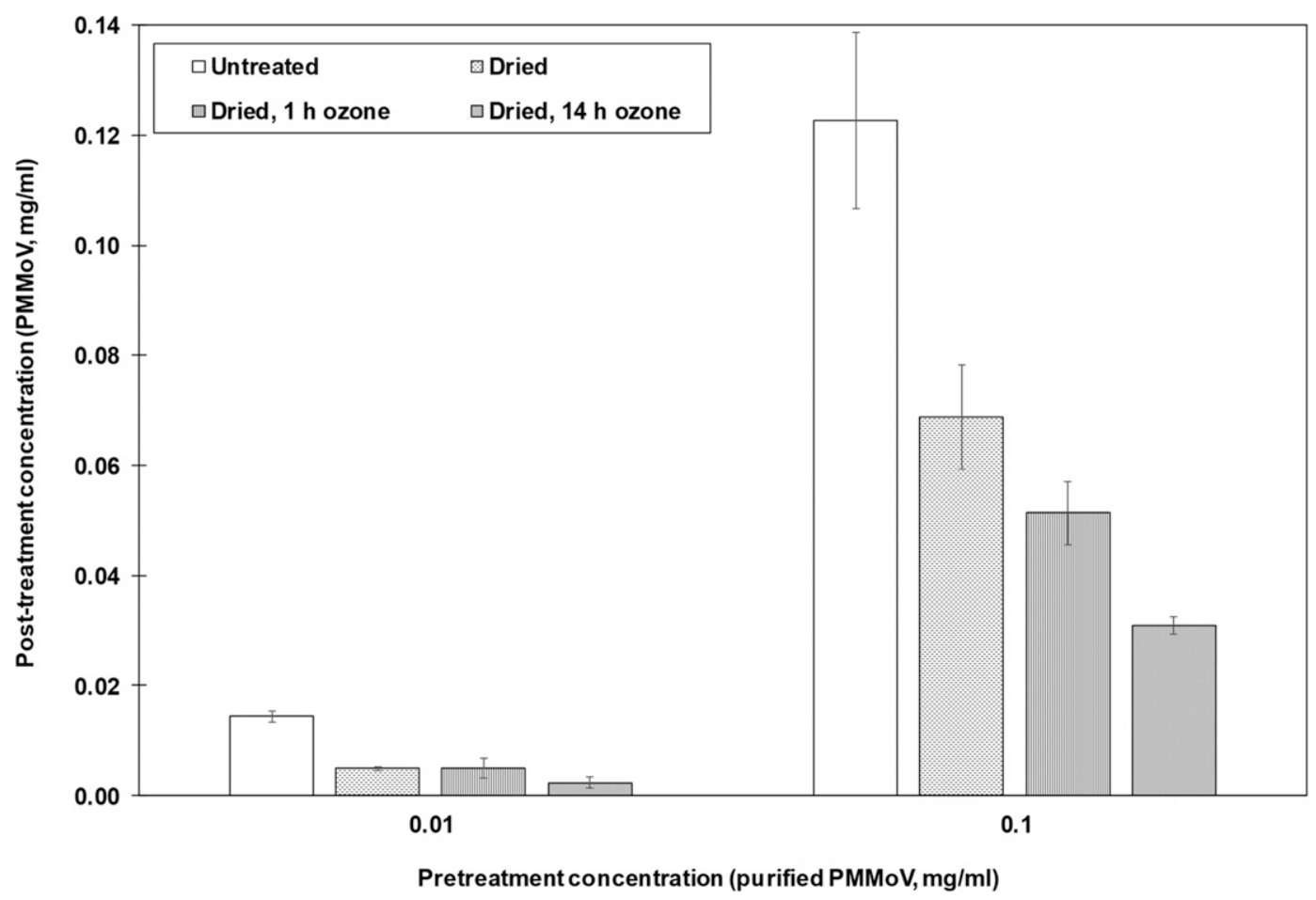

FIGURE 5

Effect of 1-h and 14-h ozone exposure and drying on pepper mild mottle virus (PMMoV) concentration in untreated and treated purified viral preparations as determined by RT-qPCR. For treated purified PMMoV samples, aliquots of 0.01 and $0.1 \mathrm{mg} / \mathrm{ml}$ of purified PMMoV were vacuum dried, exposed to ozone for $1 \mathrm{~h}$ and $14 \mathrm{~h}$, and resuspended in $50 \mathrm{mM}$ potassium phosphate $\left(\mathrm{K}_{2} \mathrm{HPO}_{4} / \mathrm{KH}_{2} \mathrm{PO}_{4}\right)$ buffer, $\mathrm{pH} 7.2$, returning samples to original volume. 
samples with less viral degradation in comparison with those with a higher level of degraded RNA. Although less quantitative, $N$. glutinosa bioassays similarly support PMMoV inactivation. The number of local lesions observed in bioassays declined with increasing ozone exposure time. Whereas drying alone resulted in reduced RT-qPCR and local lesion values, reductions did not have a marked effect on positive PMMoV infection of $N$. benthamiana. Cumulative negative effects of drying plus lengthy ozone exposure on posttreatment PMMoV concentrations and $N$. benthamiana infection were evident at low PMMoV concentrations, suggesting that drying under vacuum, which may strip the water of solvation from virus particles, renders a sufficient fraction of the virions less stable, thus reducing infection incidence when combined with ozone exposure.

Concerns regarding the effect of ozone exposure on pepper seed germination were not evident, even with 14-h exposure. Germination rates between untreated, conventional TSP treatment, and ozone were not significantly different. These results differ with reports in which TSP resulted in up to $19.5 \%$ reduced germination in some seed lots (Jarret et al. 2008). Our germination tests utilized freshly treated seed stored for short periods. Negative effects of TSP on pepper seed germination have been observed to increase with length of storage time after treatment (P. Bosland, New Mexico, personal communication). Low-dose ozone treatment is reported to enhance seed germination and seedling vigor (Pandiselvam et al. 2020).

Equipment that continuously generates ozone is advantageous for disinfection of surfaces because ozone is unstable and degrades to diatomic oxygen (Westover et al. 2020). In comparison with liquid sanitizers, gaseous ozone spreads throughout the treated area and can penetrate difficult to reach surfaces better than liquids or aerosols that may be impeded by surface tension or surface physical attributes (Hudson et al. 2009). Westover et al. (2020) evaluated the efficacy of continuously generated gaseous ozone using a Sani Sport device comparable to that utilized in our study to treat surfaces and equipment common in a hospital setting. They demonstrated up to $99 \%$ reduction of medically relevant environmental bacteria after 2 -h treatment cycles and significant reduction of SARS-CoV-2 RNA over multiple treatment timepoints with nearly complete destruction after 4-h cycles. A viricidal dose of $10 \mathrm{ppm}$ of ozone for $30 \mathrm{~min}$ has been proposed for $99 \%$ viral inactivation on contaminated personal protective equipment (Blanchard et al. 2020).

Studies to localize PMMoV in pepper seed demonstrate localization of the virus in the epidermis and parenchyma or on the surface of the epidermis and parenchyma, but not in the endosperm or embryo (Genda et al. 2005). These results support observations that extension of TSP treatments from 2.5 to $24 \mathrm{~h}$ increased effectiveness of the treatment in elimination of PMMoV contamination (Jarret et al. 2008). Increased penetration of liquid treatments via extended treatment time or addition of chemical agents that enhance penetration are likely advantageous for increased treatment efficacy. PMMoV localized on seed coat surfaces can be attacked by ozone-mediated ROS. As suggested by Westover et al. (2020), modifications of gaseous ozone flow rate, pressure, or temperature may increase the effectiveness of ozone-mediated viral destruction on contaminated surfaces. Similar to TSP treatment, virus in the epidermis and parenchyma will be difficult to degrade using ozone treatments.

\section{ACKNOWLEDGMENTS}

The work reported here was performed under Material Transfer Research Agreement 58-8020-7-004-F, with Sani DefenX/Sani Sport, St. Laurent, QC, Canada, for "Multiple Use of Ozone Generator", and provision of a Sani DefenX ST02 Ozone Sanitizing Machine and a customized control board to allow extended ozone treatment times.

\section{LITERATURE CITED}

Alonso, E., García-Luque, I., Avila-Rincón, M. J., Wicke, B., Serra, M. T., and Díaz-Ruíz, J. R. 1989. A tobamovirus causing heavy losses in protected pepper crops in Spain. J. Phytopathol. 125:67-76.

Blanchard, E., Lawrence, J., Noble, J., Xu, M., Joo, T., Ng, N., Schmidt, B., Santangelo, P., and Finn, M. G. 2020. Enveloped virus inactivation on personal protective equipment by exposure to ozone. medRxiv https:// doi.org/10.1101/2020.05.23.20111435.

Broadbent, L. 1965. The epidemiology of tomato mosaic. XI. Seed transmission of TMV. Ann. Appl. Biol. 56:177-205.

Carpendale, M. R. F., and Freeberg, J. K. 1991. Ozone inactivates HIV at noncytotoxic concentrations. Antiviral Res. 16:281-292.

Ciccarese, F., Sasanelli, N., Ciccarese, A., Ziadi, T., and Mancini, L. 2007. Seed disinfestation by ozone treatments. In: Proceedings of the IOA Conference and Exhibition. October 29-31. Valencia, Spain.

Crowley, N. C. 1957. Studies on the seed transmission of plant virus diseases. Aust. J. Biol. Sci. 10:449-464.

Demski, J. W. 1981. Tobacco mosaic virus is seedborne in pimento peppers. Plant Dis. 65:723-724.

Dyas, A., Boughton, B. J., and Das, B. C. 1983. Ozone killing action against bacterial and fungal species; microbiological testing of a domestic ozone generator. J. Clin. Pathol. 36:1102-1104.

Finch, G. R., and Fairbairn, N. 1991. Comparative inactivation of polio virus type 3 and MS2 coliphage in demand-free phosphate buffer by using ozone. Appl. Environ. Microbiol. 57:3121-3126.

Genda, Y., Sato, K., Nunomura, O., Hirabayashi, T., Ohnishi, J., and Tsuda, S. 2005. Immunolocalization of pepper mild mottle virus in Capsicum annuum seeds. J. Gen. Plant Pathol. 71:238-242.

Gooding, G. V., and Hiebert, T. T. 1967. A simple technique for purification of tobacco mosaic virus in large quantities. Phytopathology 57:1285.

Gupta, A. K., and Brintnell, W. 2014. Ozone gas effectively kills laboratory strains of Trichophyton rubrum and Trichophyton mentagrophytes using an in vitro test system. J. Dermatolog. Treat. 25:251-255.

Haramoto, E., Kitajima, M., Kishida, N., Konno, Y., Katayama, H., Asami, M., and Akiba, M. 2013. Occurrence of pepper mild mottle virus in drinking water sources in Japan. Appl. Environ. Microbiol. 79:7413-7418.

Hoff, J. C. 1986. Inactivation of Microbial Agents by Chemical Disinfectants EPA 600 S2-86 067. Office of Water, U.S. Environmental Protection Agency, Washington, DC.

Hudson, J. B., Sharma, M., and Vimalanathan, S. 2009. Development of a practical method for using ozone gas as a virus decontaminating agent. Ozone Sci. Eng. 31:216-223.

Jarret, R. L., Gillaspie, A. G., Barkley, N. A., and Pinnow, D. L. 2008. The occurrence and control of pepper mild mottle virus (PMMoV) in the USDA/ARS Capsicum germplasm collection. Seed Technol. 30: 26-36.

Kang, M. H., Pengkit, A., Choi, K., Jeon, S. S., Choi, H. W., Shin, D. B., Choi, E. H., Uhm, H. S., and Park, G. 2015. Differential inactivation of fungal spores in water and on seeds by ozone and arc discharge plasma. PLoS One 10:e0139263.

Khadre, M. A., Yousef, A. E., and Kim, J. G. 2001. Microbiological aspects of ozone applications in food: A review. J. Food Sci. 66:1242-1252.

Kwack, Y., Kim, K. K., Hwang, H., and Chun, C. 2014. An ozone microbubble technique for seed sterilization in alfalfa sprouts. Korean J. Hortic. Sci. Technol. 32:901-905.

Lamb, E. M., Adkins, S., Schuler, K. D., and Roberts, P. D. 2001. Pepper Mild Mottle Virus. HS-808. University of Florida, IFAS Extension, Gainesville, FL.

Laroussi, M. 2005. Low temperature plasma-based sterilization: Overview and state-of-the-art. Plasma Process. Polym. 2:391-400.

Lewandowski, D. J. 1999. Genus Tobamovirus. Pages 889-894 in: Virus Taxonomy: Seventh Report of the International Committee Taxonomy Viruses. M. H. V. Van Regenmortel, C. M. Fauquet, D. H. L. Bishop, E. B. Carstens, M. K. Estes, S. M. Lemon, J. Maniloff, M. A. Mayo, D. McGeoch, C. R. Pringle, and R. B. Wickner, eds. Academic Press, San Diego, CA.

Lightbourn, G. J., Stommel, J. R., and Griesbach, R. J. 2007. Epistatic interactions influencing anthocyanin gene expression in Capsicum anпиит. J. Am. Soc. Hortic. Sci. 132:824-829.

Mohan, N., Patel, K., Padmanabhan, K., and Ananthi, S. 2005. Ozone for plant pathological applications. Ozone Sci. Eng. 27:499-502.

Murray, B. K., Ohmine, S., Tomer, D. P., Jensen, K. J., Johnson, F. B., Kirsi, J. J., Robison, R. A., and O'Neill, K. L. 2008. Virion disruption by ozonemediated reactive oxygen species. J. Virol. Methods 153:74-77. 
Nagai, Y. 1981. Control of mosaic diseases of tomato and sweet pepper caused by tobacco mosaic virus. Spec. Bull. Chiba Agric. Exp. Stn. 9: 1-109.

Pandiselvam, R., Mayookha, V. P., Kothakota, A., Sharmila, L., Ramesh, S. V., Bharathi, C. P., Gomathy, K., and Srikanth, V. 2020. Impact of ozone treatment on seed germination-A systematic review. Ozone Sci. Eng. 42:331-346.

Rajkowski, K. T., and Rice, E. W. 2004. Effect of alfalfa seed washing on the organic carbon concentration in chlorinated and ozonated water. J. Food Prot. 67:813-817.

Restaino, L., Frampton, E. W., Hemphill, J. B., and Palnikar, R. 1995. Efficacy of ozonated water against various food related microorganisms. Appl. Environ. Microbiol. 61:3471-3475.

Roy, D., Wong, P. K., Engelbrecht, R. S., and Chian, E. S. 1981. Mechanism of enteroviral inactivation by ozone. Appl. Environ. Microbiol. 41: 718-723.

Shacter, E. 2000. Quantification and significance of protein oxidation in biological samples. Drug Metab. Rev. 32:307-326.

Shargil, D., Zemach, H., Belausov, E., Lachman, O., Luria, N., Molad, O., Smith, E., Kamenetsky, R., and Dombrovsky, A. 2019. Insights into the maternal pathway for cucumber green mottle mosaic virus infection of cucurbit seeds. Protoplasma 256:1109-1118.

Shinriki, N., Ishizaki, K., Ikehata, A., Nomura, A., and Mizuno, Y. 1978. Degradation of nucleic acid with ozone. Nucleic Acids Res. 5:s303-s308.
Toyoda, K., Hikichi, Y., Takeuchi, S., Okumura, A., Nasu, Y., Okuno, T., and Suzuki, K. 2004. Efficient inactivation of pepper mild mottle virus (PMMoV) in harvested seeds of green pepper (Capsicum annuиm L.) assessed by a reverse transcription and polymerase chain reaction (RTPCR)-based amplification. Sci. Rep. Fac. Agric. Okayama Univ. 93:29-32.

Trinetta, V., Vaidya, N., Linton, R., and Morgan, M. 2011. A comparative study on the effectiveness of chlorine dioxide gas, ozone gas and e-beam irradiation treatments for inactivation of pathogens inoculated onto tomato, cantaloupe and lettuce seeds. Int. J. Food Microbiol. 146: 203-206.

Westover, C., Rahmatulloev, S., Danko, D., Afshinnekoo, E., O’Hara, N. B., Ounit, R., Bezdan, D., and Mason, C. E. 2020. Ozone treatment for elimination of bacteria and SARS-CoV2 for medical environments. bioRxiv https://doi.org/10.1101/420737.

Wetter, C., Conti, D., Altscuh, R., Tabillion, R., and van Regenmortel, M. H. V. 1984. Pepper mild mottle virus, a tobamovirus infecting pepper cultivars in Sicily. Phytopathology 74:405-410.

Zhang, T., Breitbart, M., Lee, W. H., Run, J. Q., Wei, C. L., Soh, S. W. L., Hibberd, M. L., Liu, E. T., Rohwer, F., and Ruan, Y. 2006. RNA vira community in human feces: Prevalence of plant pathogenic viruses. PLoS Biol. 4:e3.

Zhao, J., and Cranston, P. M. 1995. Microbial decontamination of black pepper by ozone and the effect of the treatment on volatile oil constituents of the spice. J. Sci. Food Agric. 68:11-18. 